\title{
Arcuate graben of Venusian volcano-tectonic structures: The last phase of tectonic activity?
}

\author{
V.-P. Kostama and M. Aittola
}

\author{
Astronomy Division, Department of Physical Sciences, PO Box 3000, 90014 University of Oulu, Finland \\ e-mail: petri.kostama@oulu.fi
}

Received 25 June 2003 / Accepted 5 July 2004

\begin{abstract}
Coronae and novae are two examples of Venusian volcano-tectonic structure types. Both these structures are considered either as surface expressions of diapirs or as representations of mantle upwellings. Half of the novae are located within coronae. The recent studies show that, in contrast to the earlier assumptions, at least the last activity of the nova usually postdates the coronae formation. This is possibly due to the reactivation of the nova location or increase in the activity of the formation process of the feature (Aittola \& Kostama 2002, JGR, 107, 5112). In these cases, the most recent phases of activity are the nova related features, the radial structures and the lava flows produced by the nova. However, in some examples, suites of very young arcuate graben are seen adjoining the sloping flanks of the structures. The studies of the volcano flanks of Earth have shown that similar horseshoe-shaped scarps are formed after an eruption which indicate the occurrence of failure of the scoria cone. It is also possible to have a lateral spreading of the cone resulting in fracturing of coherent material due to plastic flow of subsequent material. We have found evidence of these graben in at least four of the studied corona-nova paired structures. In this study, we concentrate on measuring and analysing these suites of tectonic modification. As the earlier studies have shown, these corona-novae structures are usually very young in respect to their surrounding geology and thus the deformation of the lava flows, i.e. the graben sets could actually represent the last stage of development of the corona-novae structures of Venus.
\end{abstract}

Key words. planets and satellites: general - planets and satellites: individual: Venus

\section{Introduction}

Venus as a single-plate planet (Schubert et al. 1997) has a unique set of volcano-tectonic features. The large enigmatic circular structures, coronae, are of particular interest and have been objects of much research in the Venus studies. The coronae (Fig. 1a) are identified by an annulus of concentric fractures and ridges (Stofan et al. 1992; Pronin \& Stofan 1990; Barsukov et al. 1986; Basilevsky et al. 1986) created by the lithostatic pressure of the rise, its gravitational spreading and lateral pressure of flattening (Squyres et al. 1992; Janes \& Squyres 1995; Krassilnikov 2001).

Along with hundreds of coronae, there are large volcanoes and smaller structures with prominent radial features. The term nova is used to describe this special group of Venusian volcano-tectonic structures with a radiating, stellate fracture pattern (Schubert et al. 1991; Janes et al. 1992; Janes \& Turtle 1996) centered on a central summit or fracture (Fig. 1b). Also some other names such as radial corona-like feature (Stofan et al. 1992), radially fractured dome (Squyres et al. 1992), failed corona (Janes \& Turtle 1996) and stellate fracture center' or SFC (Crumpler et al. 1996) have been used. The term nova is widely used and known, so it is used also in this paper for clarification.

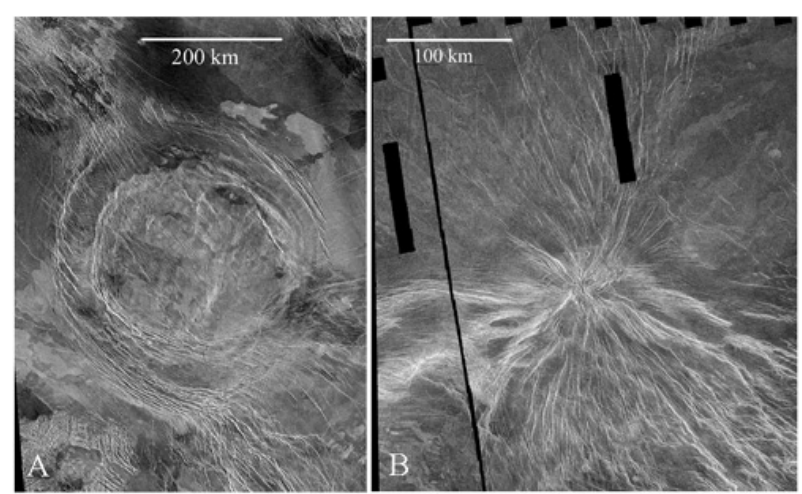

Fig. 1. a) Example of a Venusian Corona with an annulus of concentric fractures and ridges. b) Example of a Nova. The structure has prominent radial features.

Half of the novae are located in the interior part of the coronae (Aittola \& Raitala 1999). In addition, they both are proposed to represent surface expressions of diapirs or be formed by mantle upwelling (Stofan et al. 1992; Pronin \& Stofan 1990; Basilevsky et al. 1986; Squyres et al. 1992; Janes et al. 1992; Stofan \& Head 1990; Stofan et al. 1991). Futhermore, the novae have been interpreted to represent the initial stage of the corona evolution (Stofan et al. 1992; Squyres et al. 1992; 
Janes et al. 1992) and therefore are hypothesized to predate the corona rim structure (Krassilnikov 2001; Hansen et al. 1997). However, it seems that the majority of the novae which are located in the inner part of the coronae seem to actually postdate the corona formation (Aittola 2001). Although we do see radial fracturing predating corona formation, the corona annulus is cut by younger radial fracturing. We use the short term coronanovae (Aittola \& Kostama 2002) in this paper for these corona structures with novae inside them.

As the nova formation usually postdates the coronae annulus, the most recent phases of activity of corona-nova joint structures are in these cases the nova-related features, i.e. the radial structures and the lava flows produced by the nova. However, there are some examples where very young arcuate graben can be seen adjoining the structures. These archlike systems are located in the flanks of the structures and they seem to bend away from the nova center. This is in contrast to the fractures of the annulae. Therefore, they probably are of different origin.

Studies of the volcano flanks of Earth have shown that horseshoe-shaped scarps are formed after an eruption which indicate the occurrence of failure within the flanks of the volcano (Fig. 2a) (Sumner 1998). The concentric fractures and backward tilted blocks are typical of rotational slides and slumps (Záruba \& Mencl 1969) created by gravitational sliding on nova slopes (Merle \& Borgia 1996; Merle \& Vendeville 1995; Borgia et al. 2000). It is also possible to have lateral spreading of the volcanic cone resulting in fracturing of coherent material due to plastic flow of subsequent material (Fig. 2b) (Sumner 1998). Krassilnikov \& Head also noted in their study (2003) that these structures can also be products of a) lithostatic pressure of nova construction and its gravitational spreading (Merle \& Borgia 1996; Merle \& Vendeville 1995; Borgia et al. 2000); b) lateral pressure of the flattening diapir (Stofan et al. 1992; Janes et al. 1992; Koch 1994; Koch \& Manga 1996); or c) the plastic bending of a nova slope by relaxation.

\section{Examples of the Corona-novae and the associated graben}

We have found evidence of the graben in at least four of the (Aittola \& Kostama 2002) corona-nova joint structures. In this study we concentrate on measuring and analysing these suites of tectonic modification using photogeologic and topographic information from the Magellan SAR- and GTDR-data. The SAR radar data resolution is $75 \mathrm{~m} /$ pixel and GTDR data $5 \mathrm{~km} /$ pixel.

\subsection{Corona-nova $15 S / 215 E$, Mbokomu Mons}

The corona-nova centered at 15S/215E (Mbokomu Mons) shows a very prominent arched system of graben located to the southwest of the elevated nova center (Figs. 3 and 4). Actually, two separate systems can be observed. The graben are located 27 to $100 \mathrm{~km}$ to the west of the nova and they are bent away from the nova center. The graben tend to be wider close to the nova $(1.50-2.50 \mathrm{~km})$ and narrower $(0.35-0.60 \mathrm{~km})$ when they are located over $50 \mathrm{~km}$ away from the nova center.

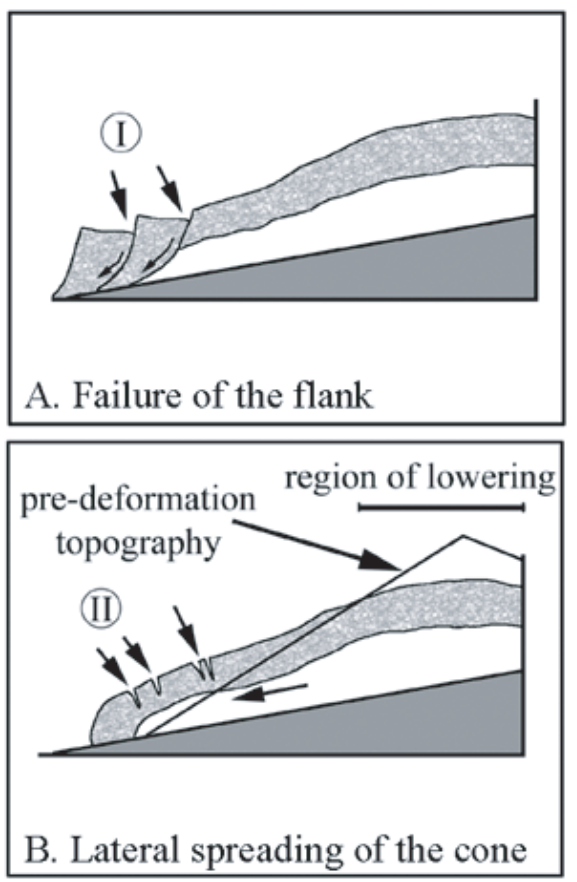

Fig. 2. The deformation of the volcanic flank. a) The rotational slumping produces backward tilted blocks and arcuate scarps (I) within the flank of the volcanic center. b) The overlying load depresses the coalesced layer which becomes unstable resulting in lateral spreading of the cone and in fracturing of coherent material (II) due to plastic flow of the subsequent material (Modified after Sumner 1998).

The length of the graben varies from $8 \mathrm{~km}$ (at distance of $85 \mathrm{~km}$ from the nova) to $35 \mathrm{~km}$ at distance of less than $50 \mathrm{~km}$ from the nova (Table 1).

The graben clearly postdate the corona-nova structures and they have deformed the lava flows associated with the latest phase of nova evolution. Thus, they represent without doubt the latest phase of activity of the corona-nova. So it is evident that the formation of the graben system is connected to the lava flow deformation probably by the gravitational sliding and slumping. This is also supported by the locations of the graben systems on the corona-nova flanks. The location of the graben sets is presented in topographical profiles of the nova flank (Fig. 4). Both sets are located on prominent slopes of the lava flows, which confirms that the graben are formed due to lateral spreading of the flows. The graben closer to the nova center appear to be located on a steeper slope, which may reflect the wider diameter of the structures compared to the graben farther from the nova. The graben located to the north-east of the nova are of different origin, they are connected to the formation of the corona annulus, and therefore predate the formation of the studied graben system.

\subsection{Corona-nova $45 S / 303.5 E$}

The corona-nova centered at coordinates $45 \mathrm{~S} / 303.5 \mathrm{E}$ shows a similar fresh-looking system of graben (Fig. 5) around an elevated nova location. Like the previous corona-nova case, there are two systems, one close to the nova center $(33-65 \mathrm{~km})$ and 


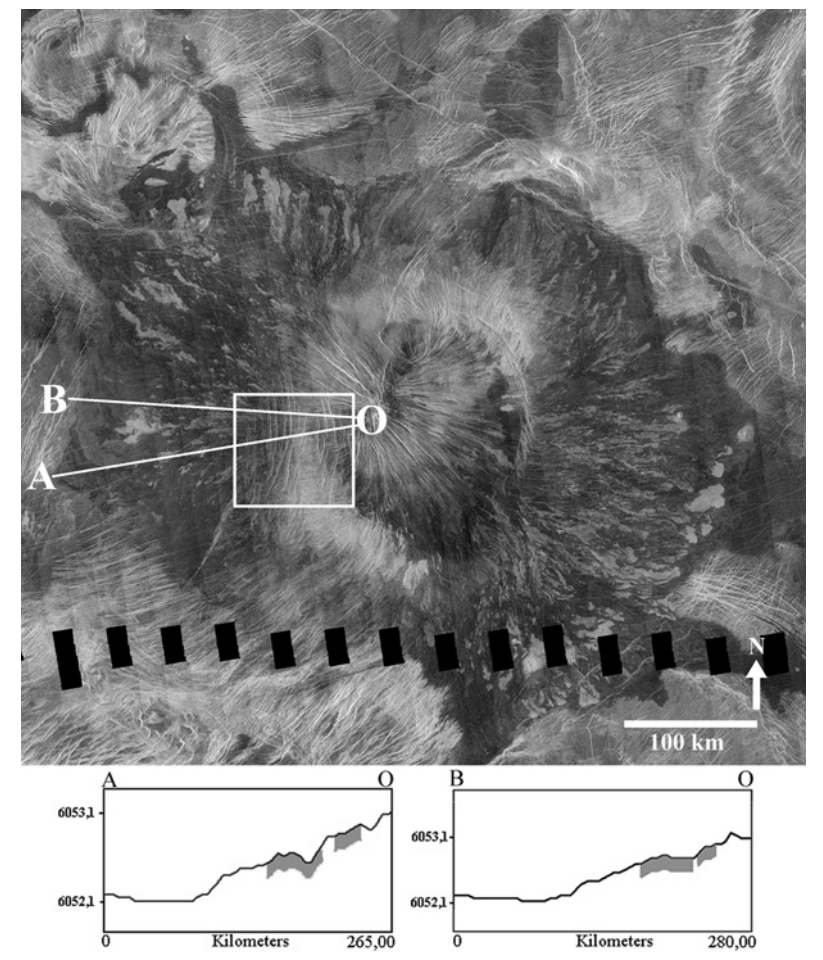

Fig. 3. The left-looking radar image of the Mbokomu Mons (from Magellan image F-MIDR.15S/215;1). This Corona-nova (15S/215E) has a prominent graben system to the SW of the Nova center. The high-resolution image of the suite (white box) is shown in Fig. 5. The topographical profiles O-A and O-B are shown with the graben regions shaded in the profile. In profile O-A the vertical enlargement is $\times 83$, and $\times 62$ in profile $\mathrm{O}-\mathrm{B}$.

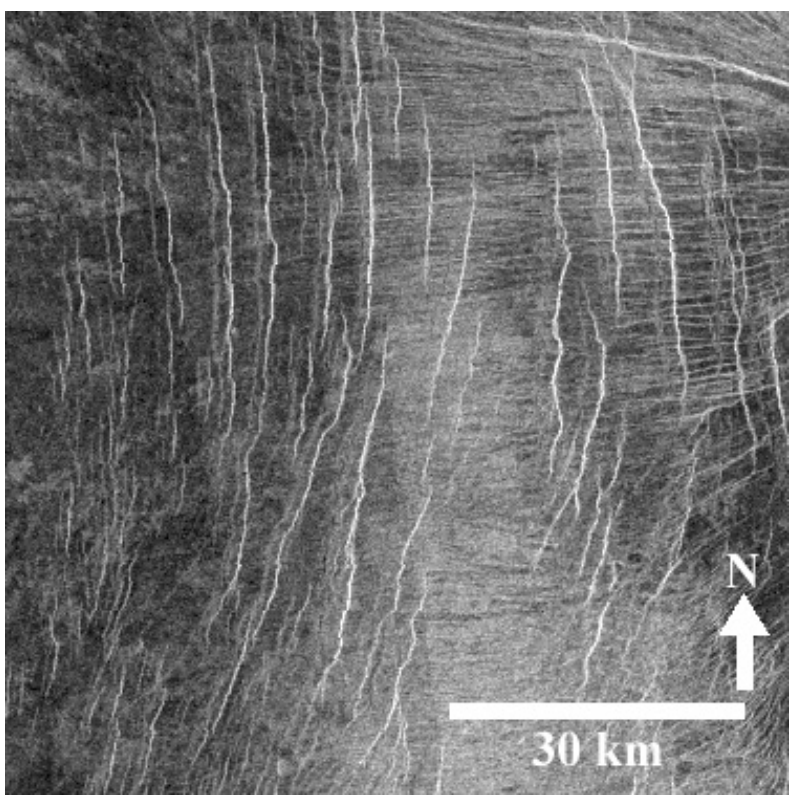

Fig. 4. The high resolution Magellan SAR image of the graben of Mbokomu Mons.
Table 1. The statistics of the studied graben systems. All measurements are in kilometers. (Distance from the center of the nova structure, the widths and lengths of separate graben). Due to the difficulties in deriving exact measurements, the corona-nova 45S/303.5E does not have widths for the graben set in $33-65 \mathrm{~km}$.

\begin{tabular}{ccc}
\hline \hline $15 \mathrm{~S} / 215$ & & \\
\hline Distance & Diameter & Length \\
\hline $27-53$ & $1.33-1.75$ & $14-35$ \\
$53-100$ & $0.96-1.17$ & $27-69$ \\
\hline $45 \mathrm{~S} / 303.5$ & & \\
\hline Distance & Diameter & Length \\
\hline $33-65$ & N/A & $40-50$ \\
$81-116$ & $1.06-1.69$ & 100 \\
\hline $14 \mathrm{~S} / 164(\mathrm{NW})$ & & \\
\hline Distance & Diameter & Length \\
\hline $140-175$ & $1.02-1.85$ & $36.7-46.8$ \\
$209-240$ & $1.02-1.85$ & $36.7-46.8$ \\
\hline $14 \mathrm{~S} / 164(\mathrm{SW})$ & & \\
\hline Distance & Diameter & Length \\
\hline $87.8-129.1$ & $0.90-1.65$ & $14-31$ \\
\hline $8 \mathrm{~S} / 243(\mathrm{NE})$ & & \\
\hline Distance & Diameter & Length \\
\hline $41.8-74.6$ & $1.62-2.66$ & $24.02-75.40$ \\
\hline $92.4-117.0$ & $0.47-0.94$ & $10.91-26.26$ \\
\hline $8 \mathrm{~S} / 243(\mathrm{SW})$ & & \\
\hline Distance & Diameter & Length \\
\hline 3 groups & $0.80-1.17$ & $21-45$ \\
\hline
\end{tabular}

the other farther $(81-117 \mathrm{~km})$ from the nova center (Figs. 5 and 6). The closer set cuts both the nova structures and the concentric structures of the corona annulus. This set of graben is located on a very steep slope facing the center of the nova. The farther one is more distinct, so it is easier to measure width and length of a single graben. The widths are rather stable at $1-1.5 \mathrm{~km}$ and the lengths vary from 33 to $70 \mathrm{~km}$. This set of graben has deformed the lava flows associated with the nova, which otherwise seem to represent the most recent activity on the region. The closer system appears to be located on a very steep flank close to the nova center (Fig. 5). In this case, however, the graben are located on a slope that is facing the nova. So these graben are probably not formed by the suggested processes, but instead represent a tectonic activity associated with the nova formation rather than the deformation of the lava flows. The graben that are located farther from the nova center are situated on the gentle slope of the lava flows. Although the source of activity forming the graben in this case is not definite (a local rift system may have some connection to their formation), this system resembles the graben of Mbokomu Mons and most probably represents the late deformation of the lava flows due to the lateral sliding. 

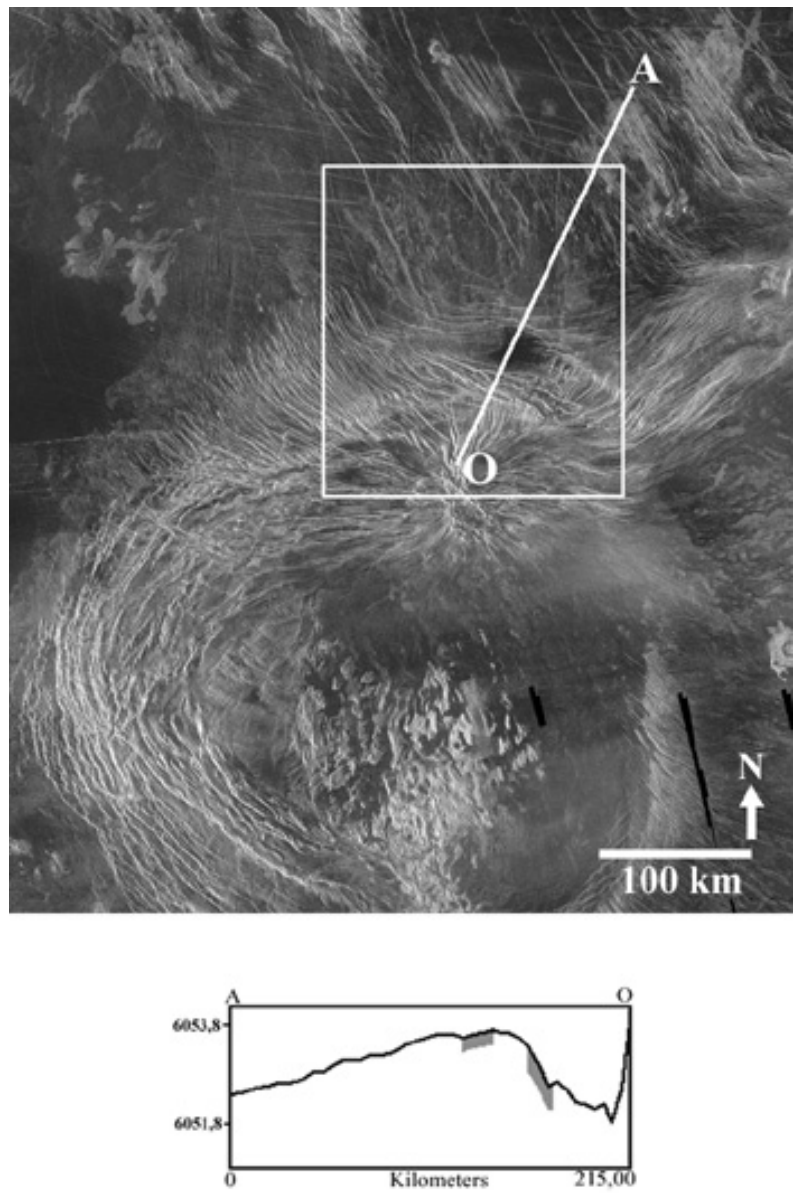

Fig. 5. The Magellan left-looking radar image of the corona-nova at coordinates $45 \mathrm{~S} / 303.5 \mathrm{E}$ (from image C1-MIDR.45S307;201). The high-resolution image of the graben (white box) is shown in Fig. 8. The topographic profile $\mathrm{O}-\mathrm{A}$ is also shown with a vertical enlargement of $\times 27$. The graben are located within the shaded regions.

\subsection{Corona-nova $8 S / 243 E$, Dhorani Corona}

The corona-nova located at 8S/243E (Dhorani Corona, Fig. 7) has a plateau-like topography with the center slightly depressed. This corona-nova is located on a NW-SE running belt of rifts. The nova is in the middle of the corona and shows some evidence of several phases or continuation of activity for a long period of time. The lava flows cover the fractures of the surrounding terrain as well as the older lava flows of the image area. It would therefore seem that the corona-nova structure or at least the latest activity phases of it are rather young.

The corona-nova has two groups of graben on the NE (Fig. 8a) and one on the SW part of the feature (Fig. 8b). The first group on the NE is located about $42-75 \mathrm{~km}$ from the nova center and the other group $92-117 \mathrm{~km}$ from the radiating point of the nova. The widths of the graben of these two groups vary remarkably. The graben that are closer to the nova are clearly wider $(0.75-2 \mathrm{~km})$ as well as longer $(19-40 \mathrm{~km})$. The graben to the SW from from the nova are situated $45-130 \mathrm{~km}$ from the nova center, both inside and outside the corona structure. The width of the graben is rather constant at about $1 \mathrm{~km}$. However, in contrast there are some variations in the lengths of the graben. The graben tend to be longer when further away

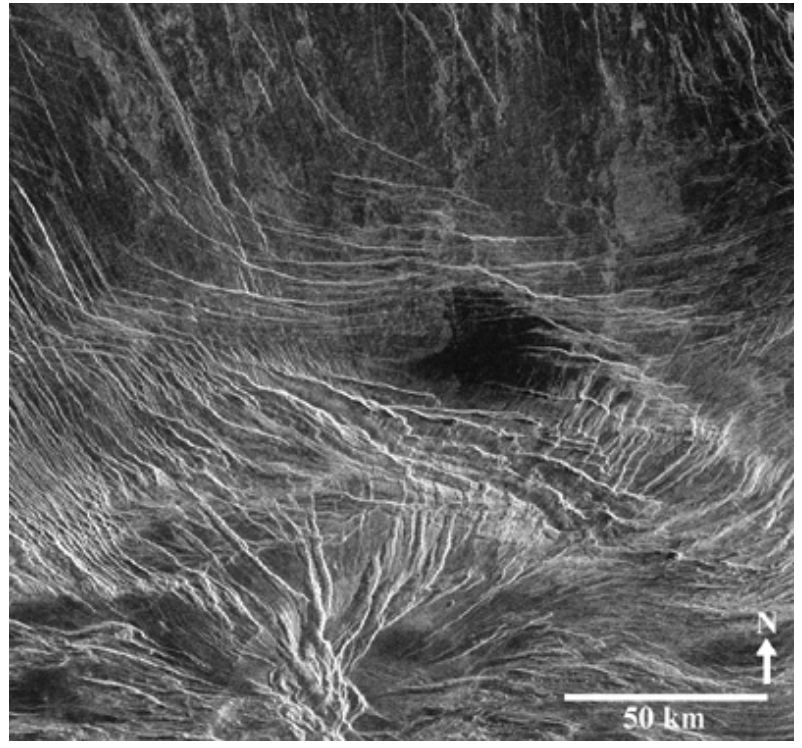

Fig. 6. The detailed image of the graben NE of Corona-nova $45 \mathrm{~S} / 303.5 \mathrm{E}$.

from the nova center and shorter in the vicinity of the nova. Nevertheless, these graben clearly postdate the emplacement of lava flows associated with the corona-nova. Thus they most probably represent the last phases of modification with this structure. Still, it should be noted that there is a rift with similar strike to the graben located in the vicinity of the corona-nova (Price 1995; Basilevsky \& Head 2000) and it may have had some influence on the graben formation process.

Figure 7 shows the locations of the graben suites in respect to the topographical profile. In almost every case the graben are found in association with slopes. This would seem to support the idea that the graben have been formed by the gravitational pull and are manifestations of post-eruption sliding/slumping processes of the lava flow.

\subsection{Corona-nova $14 S / 164 E$}

The last example, corona-nova 14S/164E (Fig. 9) shows a very prominent graben system to the NE of the nova structure (Fig. 10a). There is also a system of less explicit graben to the south of the nova center (Fig. 10b). The nova is elevated on a plateau-like corona. Due to the large size of the corona, the graben are located far from the center of the structure. The NW suite actually has two separate systems of graben. The first occurs at a distance of 140-175 km and the second at $209-240 \mathrm{~km}$. The lengths of the graben in both systems as well as the widths are quite similar. The widths of the separate graben are approximately between 1 and $2 \mathrm{~km}$ and they are of $37-47 \mathrm{~km}$ in length. The graben are located on the flanks of this joint structure, modifying the sloping lava flows. The SW group is located on a very steep slope facing the nova center (Fig. 9). The widths of graben are about $1-1.7 \mathrm{~km}$. They are $14-31 \mathrm{~km}$ long. The graben in all cases appear to be very young features. In this case the location of the corona-nova may have a profound effect on the origin of the suite of graben. It is 

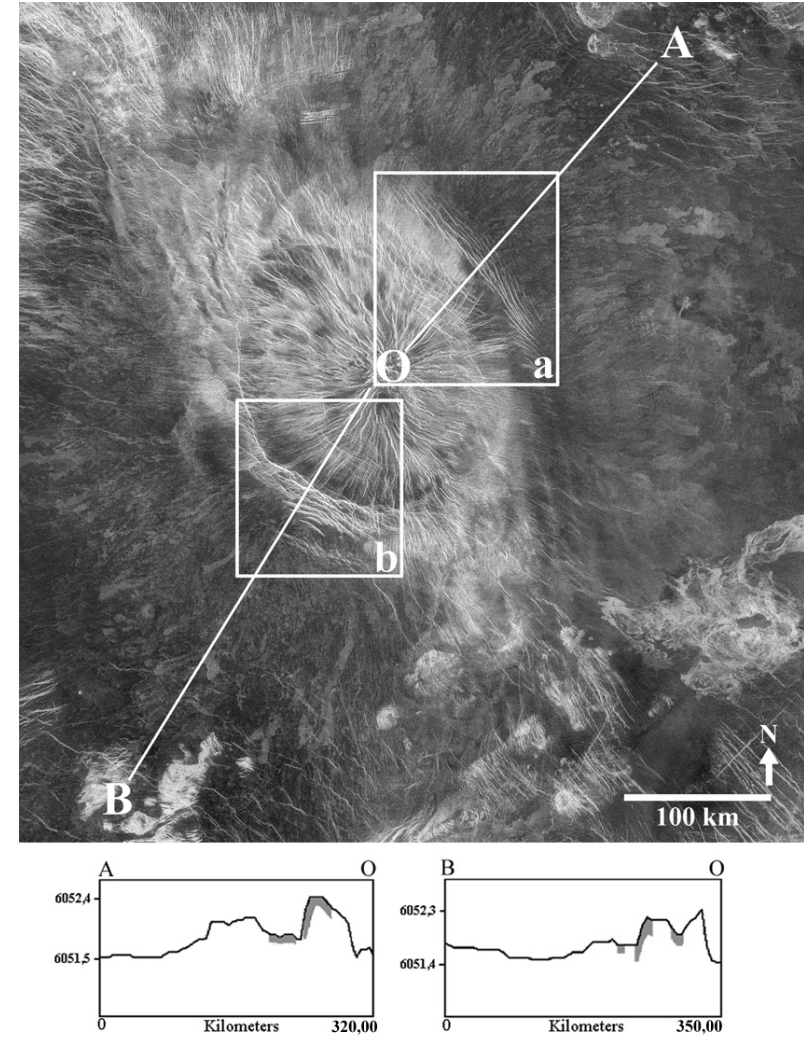

Fig. 7. The left-looking Magellan radar image of Dhorani Corona at coordinates 8S/243E (From images C1-MIDR.00N249;1 and C1-MIDR.15S249;1). The two white boxes show locations of graben in Fig. 8a (upper) and Fig. 8b (lower). The locations of the graben sets are shown within the topographical profiles O-A (with vertical enlargement of $\times 78)$ and $\mathrm{O}-\mathrm{B}(\times 76)$.
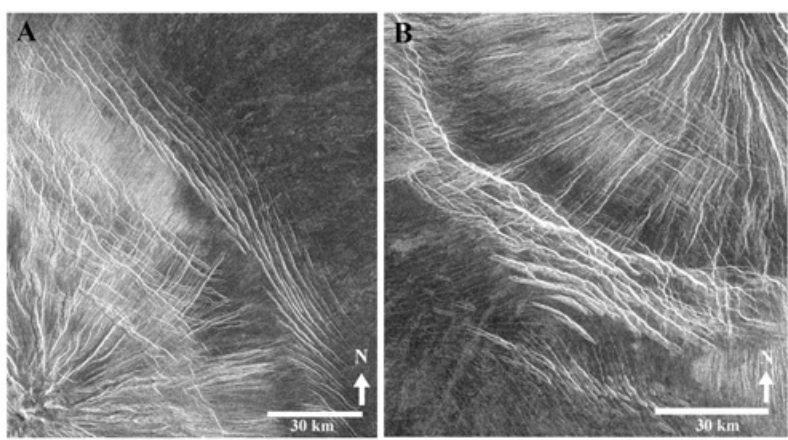

Fig. 8. a) The graben to the NE of the nova center. There are actually two separate suites modifying the flank of this structure. b) The SW graben of Dhorani Corona. Although three different suites are seen, at least the set in the middle is somewhat obscured by the fractures of the corona rim.

possible that they have not been formed by gravitational sliding, but instead by the formation of a local rift.

\section{Conclusions}

In most cases the last active phases of corona-nova evolution are the elevation of the nova with radial structures and the formation of lava flows associated with it. However, there are
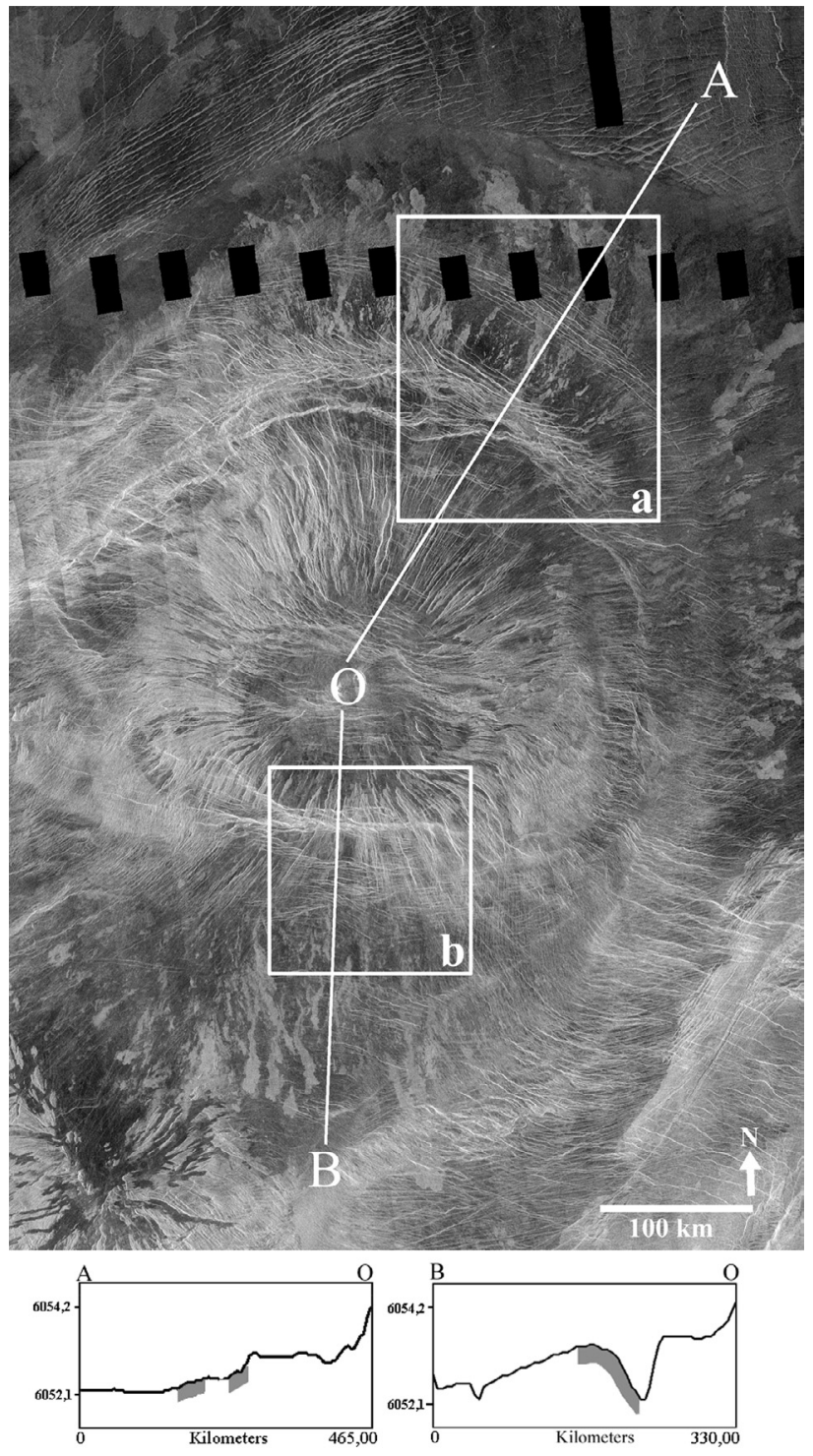

Fig. 9. The radar image (from left-looking Magellan image C1-MIDR.15S163;1) displays that the corona-nova (14S/164E) has also graben to the NE as well as to the SW of the nova center. The white boxes show locations of Fig. 10a (upper) and Fig. 10b (lower). $\mathrm{O}-\mathrm{A}$ and $\mathrm{O}-\mathrm{B}$ mark the topographical profiles with vertical exaggerations of $\times 83$ for the profile O-A and $\times 70$ for the profile O-B. The profiles have shaded areas showing the regions with graben.

some arcuate graben associated with the young lava flows of the structure, which clearly postdate the emplacement of the flows. Moreover, those graben are in most cases bent away from the corona annulus, which - together with age relations indicates that graben are not part of the corona annulus. The most likely explanation for the formation of these graben sets is the deformation mechanism of the lava flows by activities similar to landslide processes, such as slope failures (slumping and/or sliding) which produce arcuate scars or depressions on the slope. As shown in the studies of volcanoes on Earth such as the Izu-Oshima volcano in Japan (Sumner 1998), the lava flows are modified by movement of material and slope failures 

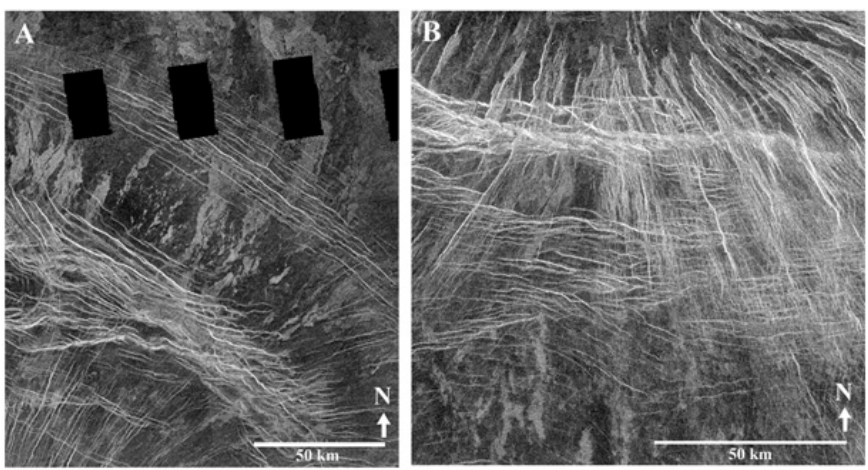

Fig. 10. a) This high resolution image show the two graben sets to the NE. They clearly postdate everything. b) This image shows the southern part of the corona-nova in coordinates $14 \mathrm{~S} / 164 \mathrm{E}$.

(gravitational slumping and/or sliding, lateral spreading) after their emplacement (Sumner 1998; Záruba \& Mencl 1969). Similar processes were suggested for Venusian nova slopes (Merle \& Borgia 1996; Merle \& Vendeville 1995; Borgia et al. 2000). It is also possible to have a lateral spreading of the volcanic cone resulting in fracturing of coherent material due to plastic flow of the subsequent material (Sumner 1998). Other possible sources for the graben are the lithostatic pressure of nova construction and its gravitational spreading (Merle \& Borgia 1996; Merle \& Vendeville 1995; Borgia et al. 2000), lateral pressure of the flattening diapir (Stofan et al. 1992; Janes et al. 1992; Koch 1994; Koch \& Manga 1996) and the plastic bending of the nova slope by relaxation (Krassilnikov \& Head 2003).

The graben found with the Venusian corona-nova structures are usually located on the slopes of the nova rise, fracturing the lava flows originating from the nova (Figs. 3, 5, 7 and 9). There may be one (Fig. 10b) or several separate systems on the same flank (i.e. Figs. 4 and 8). The graben are in general $1-2 \mathrm{~km}$ in width and occur at distances of $10-50 \mathrm{~km}$ from the nova center (Table 1). There are also secondary suites that occur at greater distances but have approximately the same width as the graben located closer to the center. Considering that these studied graben are younger than the rim fractures and lava flows, are arcuate to the direction of the flows and are located on the slopes of the volcano-tectonic structures, we conclude them to be representations of lava flow modification rather than products of endogenic exntension of the region.

These coronae with novae are usually very young in respect to their surrounding geology (Aittola 2001; Aittola \& Kostama 2002). This could imply that they are representations of some late-type activity on Venus. Thus, considering the deformation of the lava flows, the graben sets could actually represent the last stage of development of the corona-novae structures of Venus and possibly Venusian tectonics in general.
Acknowledgements. We would like to thank Barb Kilkka and Veli-Matti Pelkonen for their help with the manuscript as well as J. Raitala for his support. The constructive comments by the reviewer Anton Krassilnikov are also appreciated. This study has been funded by the Magnus Ehrnrooth Foundation and the Finnish Graduate School in Astronomy and Space Physics.

\section{References}

Aittola, M. 2001, Lunar and Planetary Science Conference XXXII, Abstract\#1503, CD-ROM

Aittola, M., \& Raitala., J. 1999, Lunar and Planetary Science Conference XXX, Abstract\#1102, CD-ROM

Aittola, M., \& Kostama, V.-P. 2002, JGR, 107, 5112

Barsukov, V. L., Bazilevskii, A. T., Burda, G. A., et al. 1986, JGR, 91, 378

Basilevsky, A. T., \& Head, J. W. 2000, JGR, 105, 24583

Basilevsky, A. T., Pronin, A. A., Ronca, L. B., \& Kryuchkov, V. P. 1986, JGR, 91, 399

Borgia, A., Koenig, E., \& Fink, J. H. 2000, Lunar and Planetary Science Conference XXXI, Abstract\#1896, CD-ROM

Crumpler, C. S., Aubele, J. C., \& Head, J. W. 1996, Venus Volcanic Feature Catalogue, http://porter.geo.brown.edu/ planetary/databases.html

Grosfils, E., \& Head, J. W. 1994, GRL, 21, 701

Hansen, V. L., Willis, J. J., \& Banerdt, W. B. 1997, in Venus II (The Univ. of Arizona Press), 797

Janes, D. M., \& Squyres, S. W. 1995, JGR, 100, 21173

Janes, D. M., \& Turtle, E. P. 1996, Lunar and Planetary Science Conference XXVII, 605

Janes, D. M., Squyres, S. W., Bindschadler, D. L., et al. 1992, JGR, 97, 16055

Koch, D. M. 1994, JGR, 99, 2035

Koch, D. M., \& Manga, M. 1996, GRL, 99, 225

Krassilnikov, A. S. 2001, Lunar and Planetary Science Conference XXXII, abstract\#1531, CD-ROM

Krassilnikov, A. S., \& Head, J. W. 2003, JGR, 108, 5108

Merle, O., \& Borgia, A. 1996, JGR, 101, 13805

Merle, O., \& Vendeville, B. 1995, Bull. Volcanol., 57, 33

Price, M. 1995, Tectonic and volcanic map of Venus (Princeton, NJ: Dept. of Geol. Sci., Princeton Univ.)

Pronin, A. A., \& Stofan, E. R. 1990, Icarus, 87, 452

Schubert, G., Solomatov, V. S., Tackley, P. J., \& Turcotte, D. L. 1997, in Venus II (The Univ. of Arizona Press), 1245

Schubert, G., Bindschadler, D., Janes, D. M., et al. 1991, EOS Trans. AGU, 72, 175

Squyres, S. W., Janes, D. M., Baer, G., et al. 1992, JGR, 97, 13153

Stofan, E. R., \& Head, J. W. 1990, Icarus, 83, 216

Stofan, E. R., Bindschadler, D. L., Head, J. W., \& Parmentier, E. M. 1991, JGR, 96, 20933

Stofan, E. R., Sharpton, V. L., Schubert, G., et al. 1992, JGR, 97, 13347

Sumner, J. M. 1998, Bull. Volcanol., 60, 195

Záruba, Q., \& Mencl, V. 1969, Landslides and their Control (Prague: Elsevier in coedition with Academia), 205 